\title{
Frontal Fibrosing Alopecia - a review and a practical guide for clinicians
}

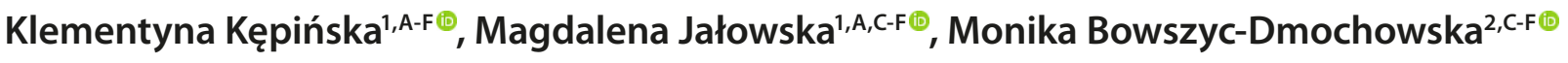 \\ ${ }^{1}$ Department of Dermatology, Poznan University of Medical Sciences, Poznan, Poland \\ ${ }^{2}$ Cutaneous Histopathology and Immunopathology Section, Department of Dermatology, Poznan University of Medical \\ Sciences, Poznan, Poland \\ A - Research concept and design, B - Collection and/or assembly of data, C - Data analysis and interpretation, \\ $D$ - Writing the article, E-Critical revision of the article, F-Final approval of the article
}

Kępińska K, Jałowska M, Bowszyc-Dmochowska M. Frontal Fibrosing Alopecia - a review and a practical guide for clinicians. Ann Agric Environ Med. 2022; 29(2): 169-184. doi: 10.26444/aaem/141324

\begin{abstract}
Despite a significant increase in reported cases of frontal fibrosing alopecia (FFA) in literature, discussion about the possible role of environmental factors, instruction for diagnosis and guideline for treatment, are limited. The review aims to provide a detailed synthesis of this condition that could be used by clinicians in their practise. Whether single-centre or multicentre, studies of more than 60 cases less than 5 years old were mainly taken into consideration. Results obtained were that FFA affects mainly postmenopausal Caucasian women; the most common comorbidities are hyperlipidaemia, arterial hypertension, osteoporosis, hypothyroidism, depression, alongside dermatological disorders such as atopic dermatitis, rosacea, seborrheic dermatitis and androgenetic alopecia. Autoimmune, genetic, hormonal (e.g. estrogen deficiency, pregnancy, lactation, HRT and raloxifene) and environmental (e.g. daily use of facial sunscreens and less frequent use of hair dyes and shampoo) hypotheses were proposed for pathogenesis, as well as association with various predisposing factors (patient's health-social profile, disease's history and comorbidities). Clinical presentation of FFA can be divided into 3 specific patterns, each with a different prognosis. Diagnosis is usually made clinically with the use of trichoscopy; however, scalp biopsy remains the gold standard. The condition is regarded as a variant of lichen planopilaris (LPP) due to the similarity of the prominent histopathological findings, but the clinical image is distinct and therapeutic options vary. 5a-reductase inhibitors, intralesional steroids, and hydroxychloroquine provide the highest level of evidence for the treatment of FFA. The conclusion is that a better understanding of the disease is crucial for proper disease management.
\end{abstract}

\section{Key words}

diagnosis, pathogenesis, treatment, environment, frontal fibrosing alopecia, medical management, primary lymphocytic cicatricial alopecia, hair loss, inflammatory hair disorder

\section{INTRODUCTION AND OBJECTIVE}

Frontal fibrosing alopecia (FFA) is a primary lymphocytic cicatricial alopecia characterised by a typical clinical pattern of progressively receding fronto-temporal hairline, with scarring that is commonly accompanied by loss of eyebrows $[1,2]$. It mainly affects postmenopausal Caucasian women $[2$, 3]. FFA is a relatively recently recognized condition, which was first described by Kossard in 1994 [4]. It is regarded as a variant of lichen planopilaris (LPP) due to indistinguishable histological results; however, the clinical image remains distinct and treatment approach varies slightly $[4,5,6,7]$ (Tab. 1). Over the last decade, the literature has reported an increasing frequency of the disease worldwide, and nowadays most dermatologists face patients with this challenging entity $[2,3,8]$. Despite this significant rise in the number of patients who search for dermatological care for FFA [8], discussion about possible environmental triggers involved in the development of the condition, instruction for diagnosis, and guideline for treatment, are limited. An initial literature review narrowed to the English language was performed using the PubMed search engine (the first access to the MEDLINE database of the National Library of Medicine was on 6 March

Address for correspondence: Klementyna Kępińska, Department of Dermatology Poznan University of Medical Sciences, Przybyszewskiego 49, 60-355 Poznań, Poland E-mail: klementynak27@gmail.com

Received: 08.11.2020; accepted: 17.08.2021; first published: 31.08 .2021
2020, with an update of the selected papers on 18 December 2020) to identify articles on 'frontal fibrosing alopecia' (487 articles of which 335 were less than 5 years old and 133 case reports), with special emphasis on those retained by applying the following conditions: article type = 'systematic review' or additional search term = 'systematic review' (6 articles); article type $=$ 'multicentre study' or additional search term = 'multicentre' (12 articles); article type = 'comparative study' or additional search term = 'comparative' (8 articles); additional search term = 'single-centre' ( 6 articles); additional search term = 'environment' or 'environmental' (16 articles). It was noted that when used alongside search term 'frontal fibrosing alopecia', the condition article type = 'guideline', 'practical guideline' or additional search term = 'guideline' returned no result. Whether single-centre or multi-centre, studies of more than 60 cases and less than 5 years old were mainly considered.

\section{STATE OF KNOWLEDGE}

\section{EPIDEMIOLOGY}

FFA is a condition mostly affecting postmenopausal Caucasian women (Fitzpatrick skin type II and III), although premenopausal onset, and cases in men have also been reported. The condition is rarely seen in other than Caucasian ethnical groups $[2,3,9,10,11]$, but this could be 
Table 1. Clinical, pathological and treatment differences between FFA and LPP

\begin{tabular}{|c|c|c|}
\hline & FFA & LPP \\
\hline \multirow{7}{*}{$\begin{array}{l}\text { Clinical } \\
\text { features }\end{array}$} & Band-like hairline recession. & Patchy diffuse alopecia on the scalp. \\
\hline & Mainly among post-menopausal women $[2,4]$. & $\begin{array}{l}\text { Observed in the middle-aged population, slightly more often in } \\
\text { women }[54,61] .\end{array}$ \\
\hline & Involvement of vellus, intermediate hairs, and just hairline terminal hairs [22]. & Terminal hair involvement [22]. \\
\hline & Frequent eyebrows involvement $[2,54,61]$. & Rare eyebrows involvement $[54,61]$ \\
\hline & $\begin{array}{l}\text { Special manifestations [54]: lonely hair sign [41], eyelash loss [2], red dots [71], } \\
\text { depression of frontal veins [71], limb hair loss [41], sideburn hair loss in males, } \\
\text { hypopigmentation in wood lamp [71]. }\end{array}$ & \\
\hline & Coexistence of other cutaneous lichen planus is rare $[41,54,61]$. & $\begin{array}{l}\text { Other forms of lichen planus may affect the skin, mucous membranes, } \\
\text { and nails. }[41,54,61] \text {. }\end{array}$ \\
\hline & Associated with androgen deficiency [72]. & Associated with androgen excess [72]. \\
\hline \multirow{3}{*}{ Treatment } & $\begin{array}{l}\text { - First line: Topical/intralesional corticosteroids (poor response), Tacrolimus (good } \\
\text { response) }[6,54,61]\end{array}$ & $\begin{array}{l}\text { - First line: Topical/intralesional corticosteroids (good response), } \\
\text { Tacrolimus (poor response) }[6,54,61]\end{array}$ \\
\hline & $\begin{array}{l}\text { - Second line (best response): 5a-reductase inhibitors }[2,6] \text {, Hydroxychloroquine [1, } \\
\text { 6, 76], Oral retinoids }[65,67,75]\end{array}$ & $\begin{array}{l}\text { - Second line (best response): Hydroxychloroquine, Oral } \\
\text { prednisolone, Mycophenolate mofetil }[6,61]\end{array}$ \\
\hline & $\begin{array}{l}\text { - Third line: Methotrexate, Combination of 5a-reductase inhibitors and oral retinoids } \\
\text { (good response), Cyclosporine, Mycophenolate mofetil (poor response) [61]. }\end{array}$ & $\begin{array}{l}\text { - Third line: Methotrexate, Cyclosporine, Pioglitazone (good } \\
\text { response), Oral retinoids (poor response) [61]. }\end{array}$ \\
\hline
\end{tabular}

Abbreviations: FFA - Frontal fibrosing alopecia; LPP - Lichen planopilaris

the consequence of a geographical selection bias $[12,13]$. Indeed, a multi-centre review of 355 patients conducted in Spain reported that $83 \%$ of the cases were postmenopausal women, $14 \%$ were premenopausal women, and 3\% were men [2]. The mean age of onset of FFA was 56 years and, apart from three women of African descent (0.9\%) and two Roma women (0.5\%), all patients were Caucasian (98.6\%) [2]. Comparable patient characteristic was reported in another large study of patients with FFA at the Mayo Clinic in the United States, although being single-centre. 148 patients were reviewed, from which $87.2 \%$ were postmenopausal women. The mean age at diagnosis was 62.1 ; also, $89.2 \%$ cases were Caucasian [9]. A similar demographic pattern has also been reported by other authors [1, 3, 4, 7, 14]. A more multi-racial multi-centre review was conducted in Brazil with 451 patients suffering of FFA which reported that $60 \%$ of the cases were postmenopausal women, $36 \%$ were premenopausal women, and $4 \%$ were men. The mean age of onset of FFA was younger (47 years old), and only $69 \%$ of patients were Caucasian [12]. The accurate prevalence of FFA, however, remains undetermined, but its incidence has increased in recent years [8].

It is important to emphasize that a considerable number of women affected by FFA had undergone hysterectomy $(11 \%-40 \%)[2,9,14,15]$, although this higher incidence was not proved to be significant in one of the largest studies [15]. Moreover, patients affected by FFA presented a higher incidence rate of early menopause (14\%) than the general population $(6 \%)[2,16]$. In addition, a history of hormone replacement therapy (HRT) was documented in $47.8 \%$ of patients, among which $63.3 \%$ reported a history of HRT use in the form of systemic estrogen and/or systemic progesterone [9]. That may suggest a hormonal role in pathogenesis of FFA. Finally, patients diagnosed with FFA tend to be non-smokers $(62 \%-87 \%)$, without any causal link being proven $[2,3,9]$.

\section{ETHIOLOGY AND PATHOGENESIS}

A more severe course of FFA seems to be related with the higher age of the patient, higher age at onset of the disease, longer duration of the disease, low academic level and higher body mass index [17]. Interestingly, many patients without evidence of previous disease developed FFA after surgery (hair transplantation or facial lifting), which could be explained by a Koebner response or a collapse of hair follicle immune privilege $[18,19,20]$. While the cause of FFA remains unknown, there are several factors that are considered to play a role in the pathogenesis of the disease:

Autoimmunization is due to the histopathological image of a dense lymphocytic infiltrate and fibrosis seen around the infundibulum and isthmus of the hair follicle [6]. The consequences of inflammation are the disappearance of sebaceous glands, definitive destruction of the follicle, and the evolution to fibrotic scar tissue [1]. Although reason for this inflammation is unknown, it is suspected that it may be a T-lymphocyte immune response driven by some specific antigen expressed by follicles [18]. It is of note that observational studies have reported a significant prevalence of auto-immune diseases in patients with FFA $[2,15,21$, $22,23]$.

Genetic background. At least four genomic loci have been significantly associated with FFA: 2p22.2, 6p21.1, 8q24.22 and $15 \mathrm{q} 2.1$ [24]. Predisposition to FFA was shown to be the highest at 6 p21.1 within the major histocompatibility complex (MHC) class I region, which was attributed to the HLA-B ${ }^{\star} 07: 02$ allele [24]. HLA-B ${ }^{\star} 07: 02$ is postulated to ease the presentation of hair follicle autoantigen, which peaks in the auto-inflammatory destruction of the hair follicle bulge by T-lymphocytes [24]. Generally, the genetic variations 
that have been found suggest that risk alleles may play a pathogenetic part, both in the antigen processing mediated by MHC class I molecules, and in T-cell homeostasis and function [24].

Hormonal factor. Estrogens participate in hair cycle control by generating a drop in the capillary stem growth and by promoting the catagen-telogen transition $[2,25]$. Menopause (natural as well as surgical) results in a decrease in serum sex steroid levels [26]. This estrogens' deficiency may alter the regulation of the hair cycle and in some matter predispose to the development of FFA [2]. This would also explain the effectiveness of treatment containing $5 a$-reductase inhibitors [27]. An androgen-driven hypothesis is also speculated given the strong association with postmenopausal status $[3,28]$. Otherwise, hormonal exposure seems also anticipated by a large study showing in women the association of FFA with pregnancy, lactation, HRT and raloxifene [15]. Interestingly, in one study, a history of oral contraceptive use was shown to be significantly lower among patients with FFA than in the control group, implying a protective role that has not yet been confirmed by recent larger studies $[15,21,23]$.

Environmental factors. In the last 15 years, FFA has become an increasingly common phenomenon observed worldwide, which has sparked speculation over possible environmental triggers in the development of this condition [8, 21, 29]. The main studies have focused on the frequencies of using sunscreens, hair dyes, shampoos, the smoking habit or on maintaining a particular diet.

Firstly, observational studies have remarkably reported a high frequency of sunscreen use in subjects with FFA $[15,21$, $29,30,31,32]$. This finding raises the question of whether sunscreen use plays a role in the disease development, which generates both interest and controversy within the medical community [13]. The link is associated particularly with facial sunscreens [15]. The popularization of sunscreens - which are nowadays also added to many beauty products such as facial moisturizers, foundations, hair shampoos and many leave-on facial cosmetics - corresponds temporally with the increasing incidence of FFA [21,29]. Several hypotheses have been proposed about how sunscreen might propagate or accelerate FFA, the dominant theory being that sunscreen enters the follicular infundibulum and triggers a lichenoid reaction, leading to the disruption of follicular immune privilege and the development of autoimmune disease [21, $29,30,31]$.

Disproportionate affection of postmenopausal women might be explained by the reduced elimination of exogenous substances from the follicular infundibulum that arises from the age-linked depletion of sebum production [29]. Another explanation might be a T-cell-mediated allergic reaction leading to the initial inflammatory state $[29,33]$. However, a group of contact allergy experts states that there is no conclusive evidence about sunscreens causing FFA by a contact allergic mechanism [34]. Another important point to mention is that the majority of the literature regards correlation between FFA and sunscreens in general without any subanalysis on sunscreen type (i.e. chemical vs physical) $[21,29,30,31]$, which seems crucial for the purpose of identifying potentially harmful substances. Nevertheless, chemical sunscreens appear to be the most commonly associated type [15]. However, it is not clear whether the more common association of FFA with chemical UV filters - compared with physical filters - results from their more widely use as active ingredients by industrial producers or from their greater attractiveness to studied patients [29]. On the other hand, abnormal deposits of titanium dioxide $\left(\mathrm{TiO}_{2}\right)$ - a physical UV filter extensively used in sunscreens - were detected along the hair shafts of patients presenting FFA $[33,35]$. In addition to its UV filter properties, $\mathrm{TiO}_{2}$ is also the most widely used white pigment in the world, with a wide range of applications, from paint and food colouring to cosmetics and skin care $[33,35]$. Classified by the International Agency for Research on Cancer (IARC) as a Group 2B carcinogen, it has been demonstrated that it can deposit in the follicular orifice $[33,36]$. But no study has yet identified the exact role of $\mathrm{TiO}_{2}$ in FFA and determined whether it is a cause, a cofactor or a consequence of the disease [37]. However, whether incorporating chemical or physical filters, regular sunscreen products, daily facial sunscreens and multiple sunscreen-containing products, were reported by a recent study to be used more frequently than normal by patients with FFA, but these were not associated with worsening disease progression in treated FFA patients [32]. Accounting for gender of patients, a large study confirmed the association of FFA with daily use of facial sunscreens in women as well as in men, but also showed the association with occupational exposure to alkylphenolic chemicals in women, and with anti-ageing creams in men [15]. Nevertheless, taking everything into consideration and because of the insufficient level of evidence for a direct causal role of sunscreens in disease development [29], one may maintain that sunscreen avoidance should not be routinely recommended to patients with FFA, especially in white populations with photodamaged skin [34].

Secondly, the frequency of shampooing and hair dyeing were proven to be significantly lower in patients with FFA in comparison with control groups [21]. Nevertheless, these findings may reflect patients' worry that hair dying and hair washing contribute to hair damage and loss, and thus their desire to minimize them [21]. An alternative explanation may simply be that frequent shampooing reduces the risk of getting FFA [21].

Thirdly, it has been suggested that exposure to tobacco may have a protective role against developing FFA $[3,38]$. Indeed, it was shown that non-smokers were the majority among patients diagnosed with FFA $(62 \%-87 \%)[2,3$, 9] and exhibited a higher prevalence of severe FFA [38]. However, a cause-effect relation remains unconfirmed $[2,3,9]$. Thus, regarding the commonly known harmful properties of tobacco, more research has to be undertaken to properly assess the effect of tobacco use on the incidence and seriousness of FFA, especially in the presence of studies that do not support the correlation $[2,15]$.

Fourthly, concerning a potential correlation between diet and development of FFA, there is insufficient data allowing its proper assessment, but a statistically higher consumption of buckwheat and millet groats was reported among patients suffering from the condition [39].

Thus, it cannot be excluded that exposure to discussed environmental factors may contribute to the development of FFA in patients with other predisposing factors, although further research must be conducted in order to provide more reliable data about possible correlations. Investigating 
environmental pathogenicity in relation to this rare disease obviously requires statistical rigor in observational studies to avoid selection bias (even with matching procedures, for instance by age, gender, menopausal status and/or skin colour), recall bias for products and frequency of use, misclassification of exposure or even temporal ambiguity in questionnaires [40]. But it also requires thinking beyond this accounting-only research to prove causality, by assessing ingredient lists of hair and facial skin care products [31], by considering geographical and cultural habits [13], and by analysing the timing of events $[13,40]$.

The most statistically significant risk and protective factors of FFA (i.e. with a margin of error less than 5\%) can be extracted from the literature, with associated odds ratios and corresponding original sources (Tab. 2).

Table 2. Significant risk and protective factors of FFA with associated odds ratios extracted from the literature

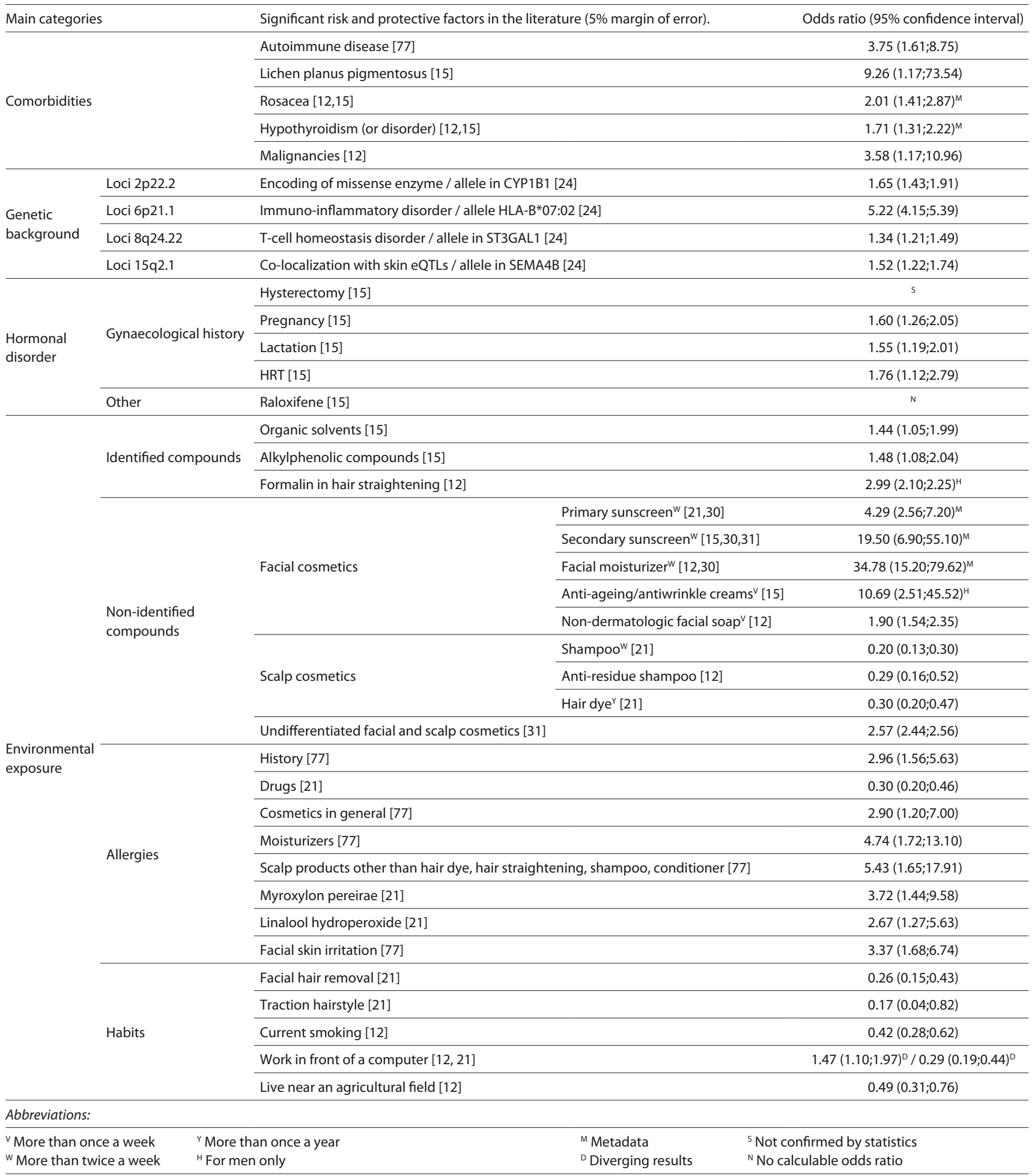




\section{CLINICAL IMAGE}

The most characteristic and distinctive clinical presentation of FFA is scarring hair loss marked by progressive recession
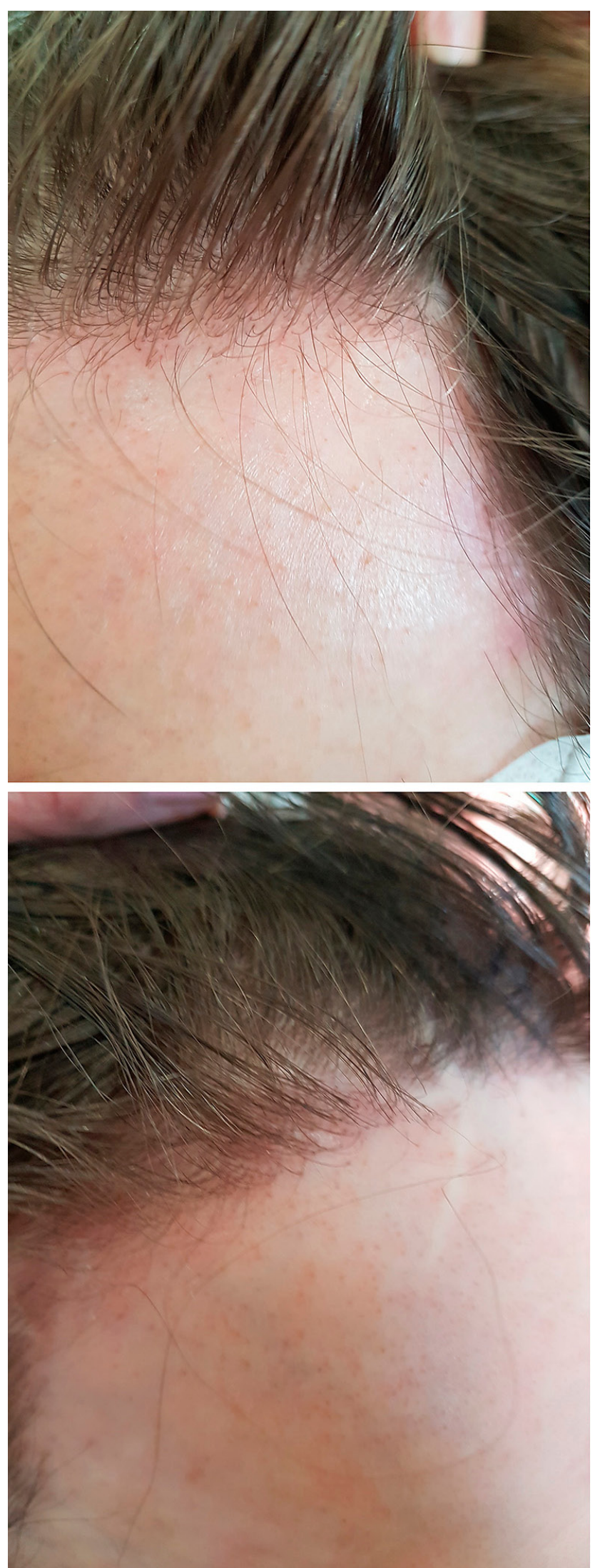

of the frontotemporal hairline (band-like recession) $[1,2,3,9$, 14, 41] (Fig. 1). The hairline generally regresses in a relatively linear fashion [3].

Clinically, one can see perifollicular erythema, follicular
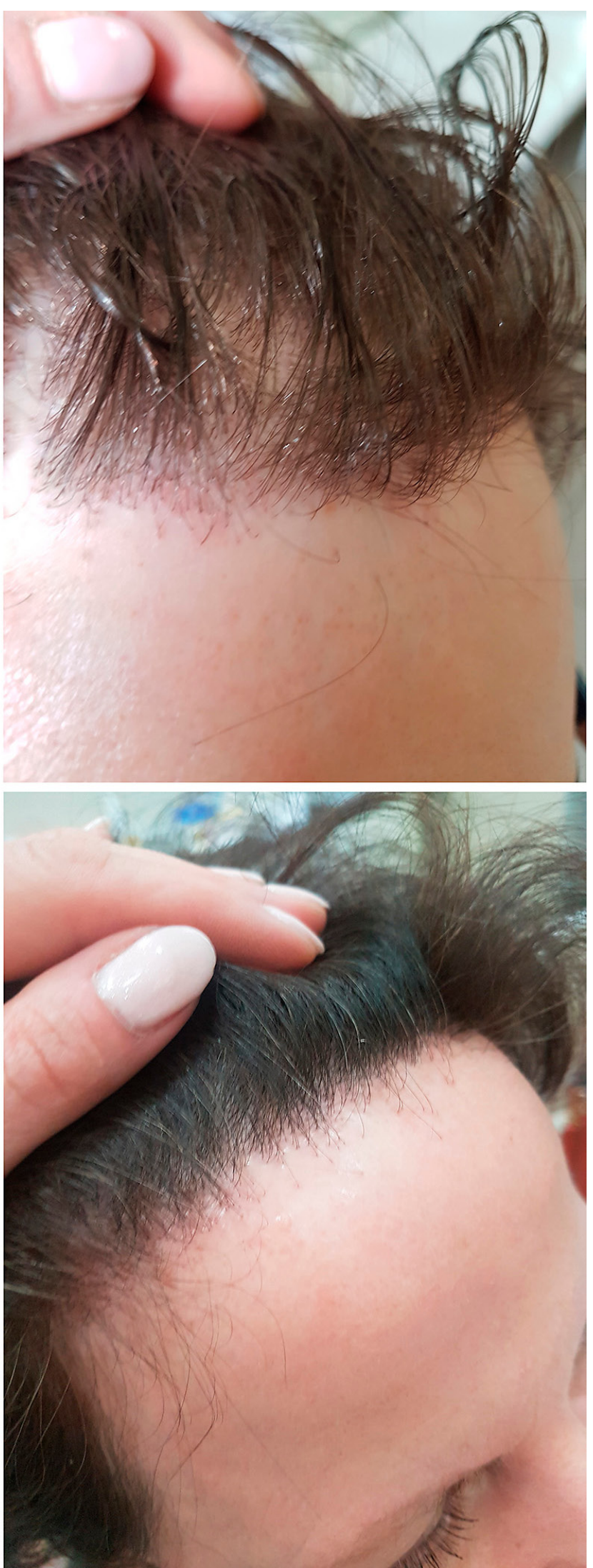

Figure 1. FFA: a classic linear pattern of hair loss (frontal recession, perifollicular erythema, the lonely hair sign) 
hyperkeratosis, and scarring affecting the frontotemporal hairline $[2,3,9,42,43,44]$. Loss of follicular orifices is also seen at the frontal scarring region $[3,7,14]$. The skin in the area of the alopecia is usually pale and contrasts with the sun-damaged skin of the lower forehead and the face [7]. If present, the 'lonely hair sign' - meaning the existence of one or a few residual terminal hairs at the initial hairline location - may help in the diagnosis of the condition $[5,45]$.

Patients with diagnosed FFA can be classified into three different clinical patterns with different prognosis [42], as described below.

Pattern I ('linear') - a band of uniform frontal hairline recession in the absence of loss of hair density behind the hairline. The most common pattern. It has an intermediate prognosis.

Pattern II ('diffuse') - a diffuse or zigzag band-like alopecia altering the frontal hairline with significant loss of hair density behind the hairline. The second most common presentation. It has the worst prognosis.

Pattern III ('pseudo-fringe sign') - retention of the hairs along the frontotemporal hairline is present. The least frequent but interestingly has the best prognosis.

Apart from the typical patterns of hair loss mentioned above, FFA can also manifest more unusual, atypical patterns sometimes called androgenetic alopecia-like pattern, cockadelike pattern and the ophiasis-like pattern, which is important to keep in mind while making differential diagnosis [46].

Among patients with FFA, eyebrow loss is frequently recorded (64\% - 95\% of cases) $[1,2,3,9,14,28,41]$. Additionally, this symptom may be the initial sign of presentation of the disease $[2,18]$. Facial vellus hairs appearing in the form of facial non-inflammatory papules are also often implicated (6\% $-37 \%$ of patients) $[2,9,14,41,47]$. On the contrary, eyelash loss is rarely reported $(3 \%-26 \%$ of cases $)[1,2,3,9,41]$.

Less frequently, FFA may also occur on other locations, such as the occipital and/or periauricular hairline and may even affect body hair, including the pubic and axillary areas, emphasizing the systemic character of this entity $[2,9,41]$. In men, alopecic regions were also recorded within the beard $[2,10]$.

Interestingly, loss of eyelashes and body hair and facial papules were correlated with severe forms of FFA, while an initial clinical presentation that included loss of eyebrows was associated with moderate forms of FFA [2]. Moreover, patients might experience pruritus, burning, and trichodynia as a result of inflammation; however, these symptoms are reported rarely, unlike LPP, and some patients even remain asymptomatic $[1,2,9,18,27,28]$.

FFA has a chronic course and is described in the literature as slowly progressing, with a possibility of stabilization that may occur spontaneously or be induced by treatment $[2,3,6$, $7,14,42,48,49] .87$ cases of FFA patients without treatment are listed in the literature, 11 of them having recovered spontaneously (13\%) [2, 14, 48, 50, 51]. Nevertheless, exact data concerning the natural course of the disease are unavailable and, since patients who eventually stabilized in a long-time follow-up were almost all under medications, it is difficult to assess whether or not the stabilizations in reviewed studies are due to implemented therapies $[1,2,6$,
$27,28,50]$. A study that included 18 female patients with FFA aged $48-88$ is in that sense very representative: 6 of them received no treatment and presented a stable condition at 2 years follow-up, whereas 5 of the other 12 who were treated either with topical steroids or with finasteride and topical minoxidil, presented a slow progression of the disease at 2 years follow-up [50]. In contrast, a case is described of a patient who abandoned treatment and a year later presented an alopecia in a 'clown-like' pattern because of a severe progression of the disease, whereas in all the other patients who kept taking their medications their condition stopped progressing [48]. Moreover, due to the cicatricial character of the disorder, the regrowth of hair, if achieved, is usually minimal [2].

The most frequently described comorbidities in patients with FFA are: hyperlipidemia, arterial hypertension, osteoporosis, hypothyroidism ( $11 \%-44 \%$ of patients), depression, and when it comes to the dermatological disorders: atopy, LPP, rosacea, seborrheic dermatitis and androgenetic alopecia $[2,3,9,11,14,15,41]$. Also, a recent study of 490 cases claims that patients with FFA exhibited a higher rate of thyroid disease than the European population, and that this comorbidity was the most common among them [11]. Of note, positive anti-thyroid antibodies and positive antinuclear antibodies are also detected in some cases [2, $9,11]$. In addition, as previously mentioned, a considerable number of patients with FFA have undergone hysterectomy $[2,9,14,15]$. Previous history of cutaneous or mucosal lichen planus is rarely reported $[2,3,9]$.

\section{DIAGNOSTIC METHODS}

Clinical examination. Due to a characteristic clinical pattern, the disease can be easily and effectively diagnosed clinically. In order to facilitate the identification of FFA, 10 signs have been established which may help clinicians in their everyday practice [52]:

1) high hairline due to cicatricial hairline recession;

2) difference in skin colour: pale skin of the affected area contrasts with normal facial skin containing signs of photodamage;

3) contraction of the frontal muscle (promoted by requesting the patient to raise the eyebrows) allows differentiation between frontal wrinkles and the marginal region of the scalp;

4) bilateral eyebrow loss;

5) more evident frontal veins: can be detected by palpation as a localized depression, near the original hairline, probably due to cutaneous atrophy;

6) disappearance of the vellus at the scalp hairline;

7) lonely hairs;

8) pseudo-fringe sign;

9) facial papules;

10) association with lichen planus pigmentosus; occurs frequently in patients with higher skin phototypes over photo-exposed areas.

Trichoscopy (dermoscopy of the hair and scalp). A very helpful and non-invasive method for correct diagnosis of the disease and carefully monitoring response to therapy (Fig. 2). The most frequent trichoscopic observations of FFA are, in decreasing order [53]: 


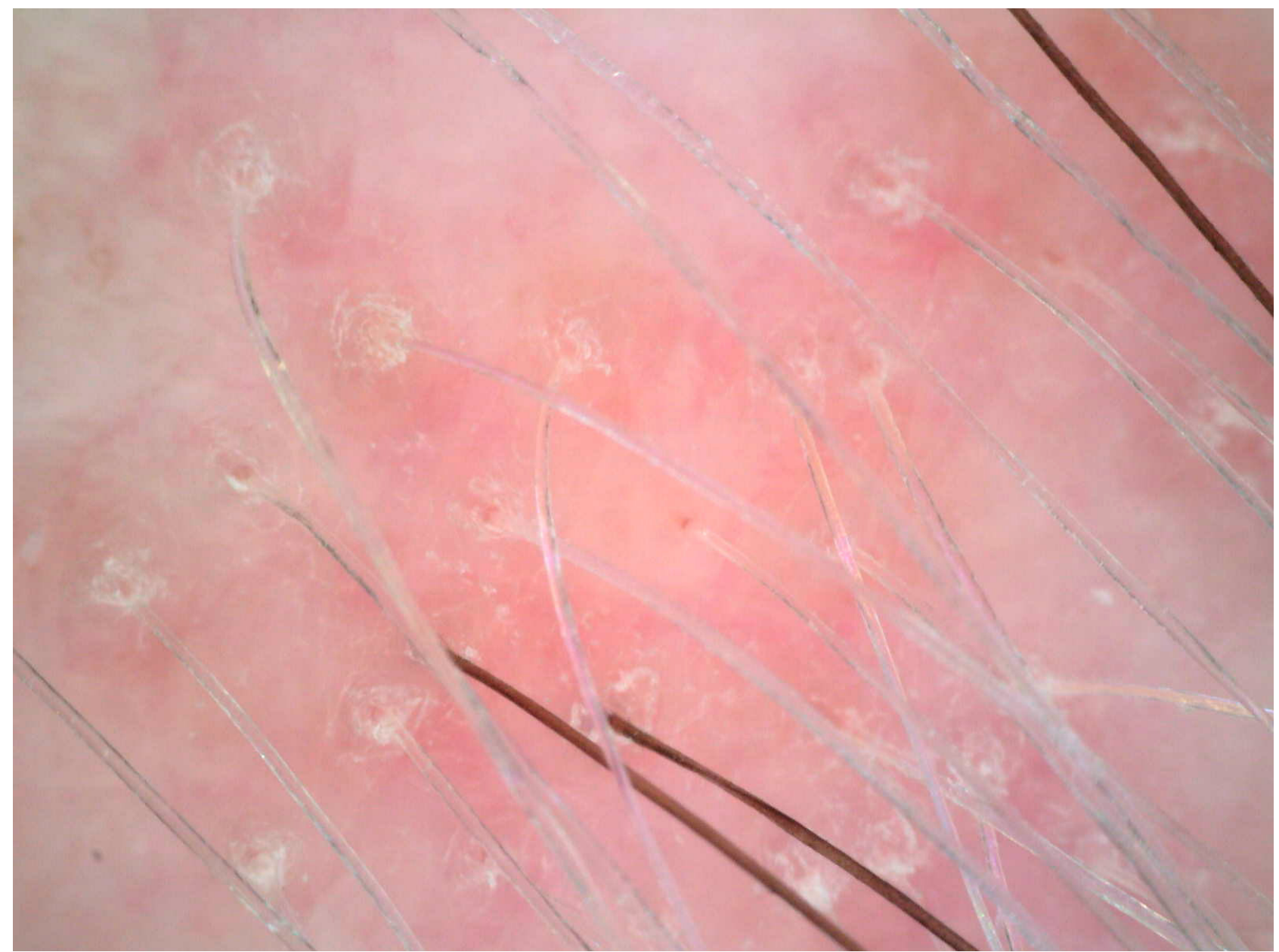

Figure 2. Trichoscopy findings in FFA: loss of follicular openings, peripilar casts and perifollicular erythema, absence of vellus hair

- perifollicular scaling;

- absence of follicular openings;

- perifollicular erythema;

- white cicatricial zones.

Less frequently, blue-grey dots and classic white dots are described [53].

Moreover, FFA activity markers are perifollicular erythema and scaling, while FFA severity markers are perifollicular erythema and white cicatricial zones [53].

In the eyebrow area, dermoscopic features of FFA include follicular red and grey dots, black dots, yellow dots, diffuse erythema, broken hairs, short regrowing hairs and absence of follicular openings, while characteristics for the scalp FFA, i.e. perifollicular erythema or scaling, are not found [53].

Trichoscopic findings in FFA are similar to those of LPP; however, the frequency of each feature differs depending on diagnosis [53, 54] (Tab. 3).

It is important to emphasize that, in order to prevent invasive procedures such as scalp biopsy, a histological examination may be substituted by typical dermoscopic features together with a characteristic clinical presentation $[2,53]$.

Histopathologic examination (biopsy). Regarded as the gold standard method of diagnosis in primary cicatricial alopecia [53]. As previously stated, because of its invasiveness, such a procedure may nevertheless be unnecessary among patients with typical outcome of the disease, although it should be performed in any case of doubt, as well as in premenopausal women and in men $[2,53]$.

Histology typically shows lymphocytic infiltrates of variable density around the infundibulum, isthmus and bulge portions of affected hair follicles, together with follicular interface changes in the early inflammatory stage $[1,7]$. A perifollicular ring of mucinous fibrosis separates the infiltrate from the outer follicular sheath in the fully developed stage. There is also an increased number of telogen and catagen hairs (Fig. 3). The loss of sebaceous glands and reduction in the number of hair follicles that are replaced with fibrotic scar tissue characterize the late fibrotic stage $[1,7,14,43,44]$.

Histological changes are identical to LPP [7].

Ultrasonography (USG). A fast and non-invasive diagnostic and follow-up imaging method which is increasingly used in the field of dermatology. Described recently, the ultrasonographic signs associated with FFA are [55]:

- hypoechoic perifollicular thickening;

- increased dermal vascular flow;

- presence of one or more frontal veins at the dermohypodermic level.

Elastography. Does not seem to be an adequate modality for an early diagnosis of FFA [55]. 


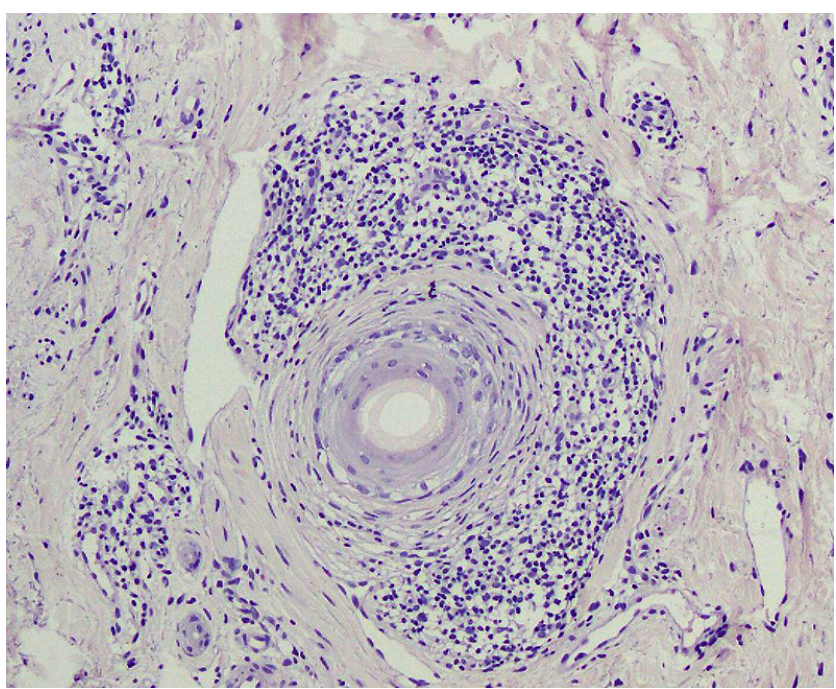

Figure 3. FFA histopathology of the active inflammatory stage. Dense perifollicular lymphocytic infiltrate surrounding the upper part of hair follicle, separated by the ring of perifollicular mucinous fibrosis. Hydropic degeneration of the basal cells of the outer root sheath. (H+E original objective magnification $20 \times$ )

Direct cutaneous immunofluorescence (DIF). Usually negative in FFA patients [56], although it can be positive in a considerable number of patients presenting LPP; therefore (also with regard to distinct clinical presentation) it may be accurate to describe FFA as a separate disease process $[18,56]$.

Hair pull test. Positive at the margins of affected zones, during the active phases of the disease, even without clinical evidence of inflammation [18].
There are no official criteria for making a diagnosis of frontal fibrosing alopecia that have been accepted by dermatologic societies, although some criteria proposed in the literature appear to be helpful $[7,43,44,57]$ (Tab. 4). Diagnosis requires either 2 major criteria or 1 major and 2 minor criteria.

Early and correct diagnosis is fundamental for establishing adequate treatment to reduce symptoms, disease progression and scars, as well as minimising the impact on the patient's quality of life.

\section{DIFFERENTIAL DIAGNOSIS}

The differential diagnosis for FFA commonly includes such disorders as:

- Lichen planopilaris (Tab. 1).

- Androgenetic alopecia.

- Central centrifugal cicatricial alopecia.

- Keratosis follicularis spinulosa decalvans.

- Discoid lupus erythematosus.

- Pseudopelade of Brocq.

- Alopecia areata.

- Traction alopecia.

- Trichotillomania.

- Graham-Little-Piccardi-Lassueur syndrome.

While making a differential diagnosis it is most important to establish whether the patient's alopecia is primary noncicatricial or cicatricial because of extremely different prognosis and treatment management (Tab. 5).

Table 3. Most common trichoscopic findings in FFA and LPP

\begin{tabular}{|c|c|c|}
\hline & $\begin{array}{l}\text { FFA Mean frequency in \%* } \\
\text { (reported prevalence }^{* *} \text { ) }\end{array}$ & $\begin{array}{l}\text { LPP Mean frequency in } \% * \\
\text { (reported prevalence }^{* *} \text { ) }\end{array}$ \\
\hline Perifollicular erythema & $68(0-100)$ & $43(0-88)$ \\
\hline Classic white dots & $13(0-50)$ & $32(0-100)$ \\
\hline Milky-red areas & Not reported & $33(14-100)$ \\
\hline White cicatricial areas & $26(20-100)$ & $84(0-100)$ \\
\hline Absence of follicular openings & $82(52-100)$ & $99(75-100)$ \\
\hline Blue-grey dots & $25(0-50)$ & $32(0-56)$ \\
\hline
\end{tabular}

Abbreviations: FFA - Frontal fibrosing alopecia; LPP - Lichen planopilaris.

*Calculated by dividing the total number of patients with a particular feature by the total number of patients in studies reporting the frequency of this feature.

**Given for the trichoscopic features for which the frequency was evaluated.

Note: Extracted from Waśkiel, Rakowska, Sikora et al. [53] with permission from Termedia.

Table 4. Set of diagnostic criteria for FFA successively developed in the literature $[7,43,44,57]$

\section{Criteria}

Major:

1. Cicatricial alopecia of the frontal, temporal, or frontotemporal scalp on examination, in the absence of follicular keratotic papules on the body;

2. Diffuse bilateral eyebrow cicatricial alopecia.

Minor:

1. Perifollicular erythema, perifollicular hyperkeratosis, or solitary hairs on physical or trichoscopic examination in a field of frontal/frontotemporal cicatricial alopecia;

2. Histopathologic features of cicatricial alopecia in the pattern of FFA or LPP on biopsy*;

3. Involvement (hair loss, perifollicular erythema, or perifollicular hyperkeratosis) of additional FFA sites: occipital area, facial hair, sideburns, or body hair^;

4. Non-inflammatory facial papules;

5. Preceding or concurrent symptoms, such as pruritus or pain, at areas of involvement.

Diagnosis requires 2 major criteria or 1 major and 2 minor criteria.

Abbreviations: FFA - Frontal fibrosing alopecia; LPP - Lichen planopilaris.

* Peri-infundibular and peri-isthmal lymphocytic inflammation, interface changes at the infundibular-isthmal epithelium, peri-infundibular and peri-isthmal fibrosis, increased hair in the catagen and telogen phases, and polytrichia.

$\wedge$ Involvement of locations associated with LPP, such as the vertex or occipital scalp, does not preclude diagnosis of FFA.

Note: Extracted from Tolkachjov, Chaudhry, Imhof et al. [44], with permission from Elsevier. 
Table 5. Cicatricial or non-cicatricial features of different types of alopecia for the purpose of differential diagnosis

\begin{tabular}{|c|c|c|c|}
\hline Type of alopecia & Cicatricial & Non-cicatricial & Commentary \\
\hline LPP & $\mathrm{X}$ & & FFA is considered a variant of LPP (Tab. 1, Tab. 3). \\
\hline $\begin{array}{l}\text { Graham-Little-Piccardi-Lassueur } \\
\text { syndrome }\end{array}$ & $\mathrm{X}$ & $\mathrm{x}$ & $\begin{array}{l}\text { Disorder from LPP spectrum. Presents characteristic triad [78]: } \\
\text { Cicatricial alopecia of the scalp; } \\
\text { Non-cicatricial alopecia of the axillary and pubic region; } \\
\text { Diffuse lichenoid follicular papules (limbs, trunk, face). }\end{array}$ \\
\hline Discoid lupus erythematosus & $\mathrm{X}$ & & $\begin{array}{l}\text { One of the most frequent causes of scarring alopecia. Similar discoid plaques are seen on } \\
\text { the scalp and face. }\end{array}$ \\
\hline Pseudopelade of Brocq & $\mathrm{X}$ & & Idiopathic, small patches of alopecia, diagnosis is made after excluding other causes. \\
\hline Central centrifugal cicatricial alopecia & $\mathrm{x}$ & & Usually present in African descent women. Premature desquamation of the inner root sheath. \\
\hline Keratosis follicularis spinulosa decalvans & $\mathrm{x}$ & & Rare genetic condition. \\
\hline Androgenetic alopecia & & $\mathrm{x}$ & May also coexist with FFA in up to $40 \%$ of patients [2]. \\
\hline Alopecia areata & & $\mathrm{x}$ & Round patches of hair loss, sudden onset. \\
\hline Traction alopecia & $\begin{array}{c}\text { Possible } \\
\text { in late stages }\end{array}$ & $x$ & $\begin{array}{l}\text { History of frequent wearing of hairstyles, such as very tight ponytails, braids, chignons, etc; } \\
\text { may coexist with FFA. }\end{array}$ \\
\hline Trichotillomania & $\begin{array}{l}\text { Possible } \\
\text { if repeated }\end{array}$ & $x$ & $\begin{array}{l}\text { Mental disorder, patient feels urged to pull out his/her own hair, a psychiatric consultation } \\
\text { may be needed. }\end{array}$ \\
\hline
\end{tabular}

\section{DISEASE ASSESSMENT}

In order to make a proper therapeutic decision, an assessment of severity of the disease is necessary before starting the treatment. Although there are no official scores, the Frontal Fibrosing Alopecia Severity Score (FFASS), a statistically validated scale that could be used in clinical practice and future research studies as an assessment tool [58], may be useful. Another useful score might be the Frontal Fibrosing Alopecia Severity Index (FFASI), a proven clinical scoring system that can provide a standardized framework for FFA assessment and patient stratification [49].

With regard to assessment of the treatment results, the literature agrees that the critical measure should be the hair loss progression $[2,6]$.

The treatment response can be clinically easily evaluated on a 3-point scale: worsening (hairline recession is progressing), stabilization (hairline recession has stopped), or improvement (hairline is regrowing) [2].

\section{TREATMENT}

Although FFA may eventually stabilize without intervention, the time course is unknown and treatment is recommended to prevent further hair loss, and possibly rescue hair follicles.

The treatment of FFA is challenging because there are no guidelines and the efficacy of different modalities is difficult to assess because most data in the literature are limited to case reports and case series [27]. Monotherapy is seldom used, and most patients reported in the literature are treated with a combination of therapies [27].

Current treatment modalities used in the treatment of FFA, their effectiveness (Tab. 6) and their adverse effects (Tab. 7) are listed below.

Topical corticosteroids / topical calcineurin inhibitors. Typically considered first-line therapy of inflammatory hair disorders; however, in case of FFA, monotherapy is mostly unsuccessful and in combination with other agents the results are variable [5, 27] (Tab. 6). Regarding the choice of topical treatment, it has been demonstrated that patients treated with $0.3 \%$ tacrolimus were significantly more likely to stabilize in 3 months, compared with patients treated with clobetasol/betamethasone [59]. Aggregation of data in the literature gives an overall positive response of $64-66 \%$ to topical corticosteroids or calcineurin inhibitors, but only $1-3 \%$ of positive cases under monotherapy (Tab. 6).

Intralesional Triamcinolone acetonide injections (TAC). One of the most beneficial therapies and preferred treatment modality for FFA, resulting in a positive treatment response in $88 \%(181 / 204)$ of patients reviewed by a recent study [27]. In more severe cases, it might be coupled with $5 a$-reductase inhibitors. Telangiectasias and skin atrophy are likely adverse effects associated with intralesional steroid treatment [60] (Tab. 7).

Topical minoxidil. Can be used in all patients with alopecia to help mask the deficit from the primary process [27]. Its most efficient use may be as adjuvant therapy, coupled with other treatments for FFA [5], with a 73\% positive response rate observed in the literature (Tab. 6).

$\mathbf{5 a}$-reductase inhibitors (5a-RIs). Considered the most effective oral therapy for FFA [2, 5, 27, 61]. Finasteride 1-5 mg/ day and dutasteride $0.5 \mathrm{mg} /$ day stabilized hair loss in $88 \%$ $(158 / 180)$ of all patients reviewed by the same study, than that cited for TAC [27]. Among them, the most interesting and relevant are cases recorded by a multicentre study of 355 patients who were given $2.5-5 \mathrm{mg} /$ day of finasteride as mono or combination therapy, resulting in an improvement of FFA in $47 \%$ of cases, and stabilization of FFA in $53 \%$ of cases [2, 27]. Another group of patients received $0.5 \mathrm{mg}$ weekly of dutasteride as mono or combination therapy, resulting in an improvement in $44.4 \%$ of cases and in a stabilization in $55.6 \%$ of cases [2]. Additionally, $5 \alpha-$ RIs are regarded as being safe, although potential side-effects include feminization of the male foetus in a pregnant woman [62] (Tab. 7). This is the reason for warning patients against becoming pregnant while on these medications, and starting birth control is recommended before initiating treatment. In women of childbearing age, finasteride is preferred over dutasteride due to its shorter half-life [62]. 


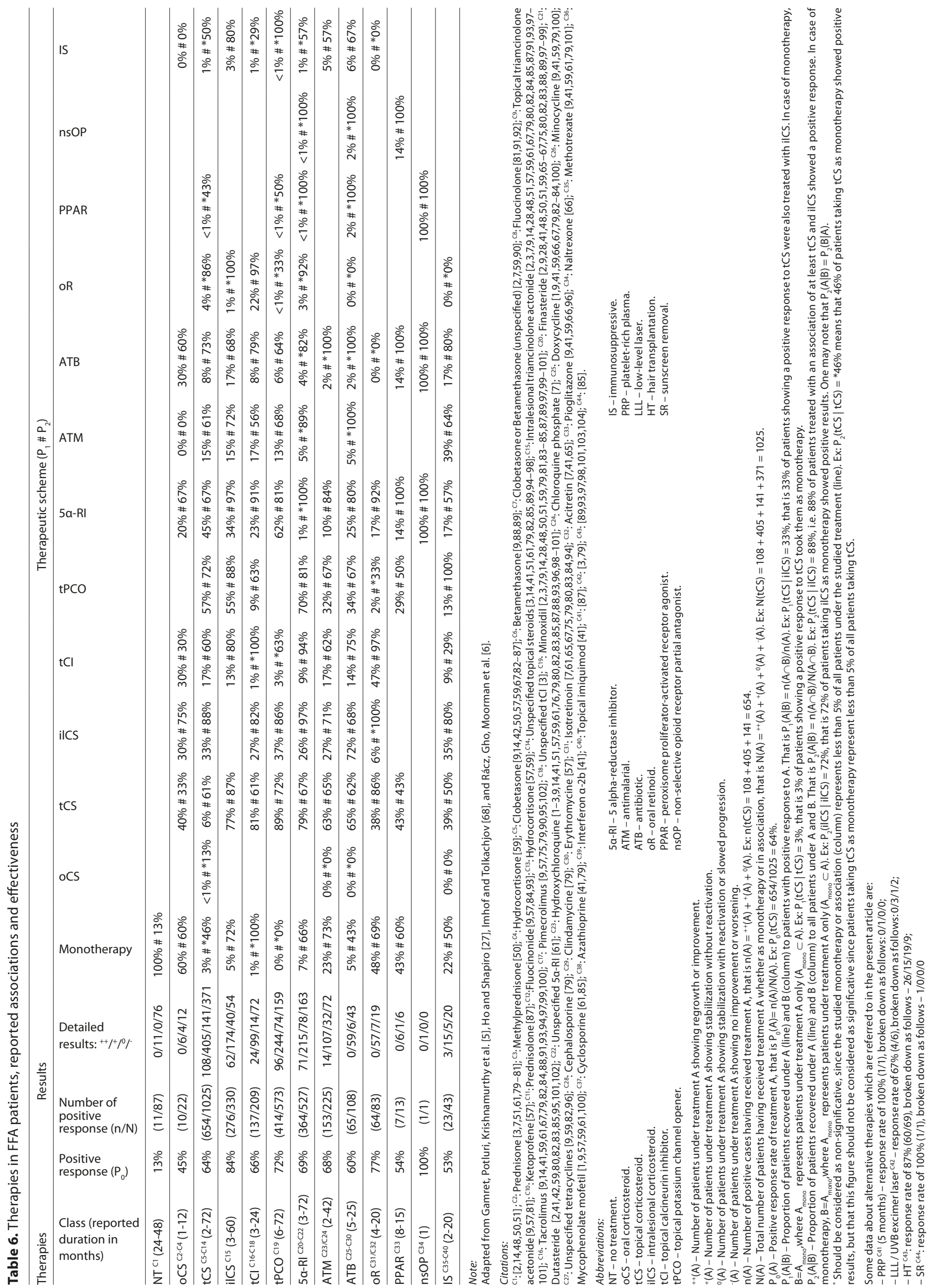


Table 7. Reported side-effects of therapies in FFA patients

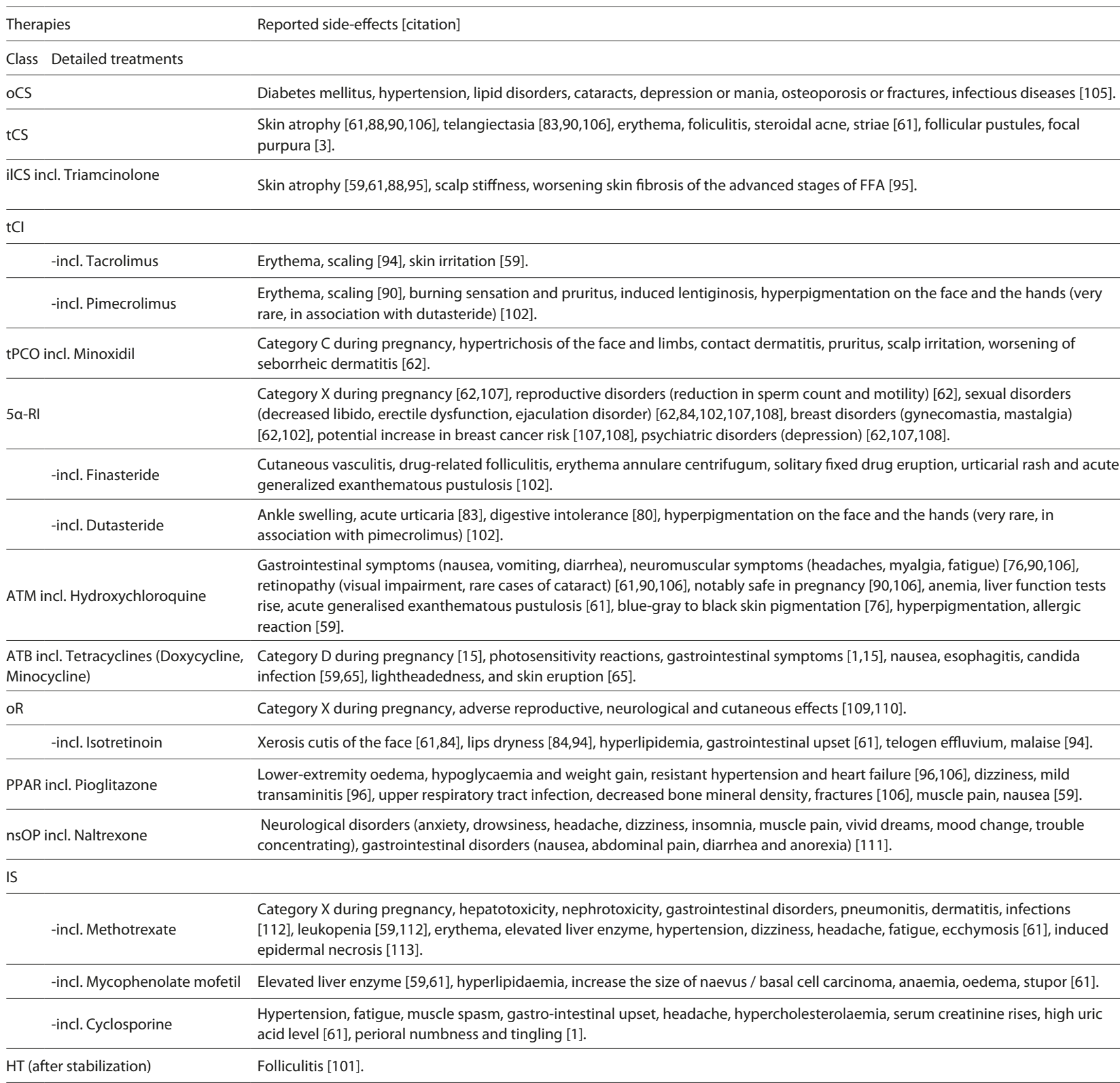

Note: Adapted from Gamret, Potluri, Krishnamurthy et al. [5], Ho and Shapiro [27] and Imhof and Tolkachjov [68].

Abbreviations:

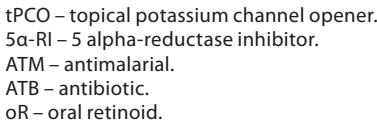

PPAR - peroxisome proliferator-activated receptor agonist. nsOP - non-selective opioid receptor partial antagonist. IS - immunosuppressive. HT - hair transplantation.
Hydroxychloroquine. An anti-malarial drug prescribed frequently as first-line systemic treatment due to its anti-inflammatory properties and low side-effect profile [27]. Doses ranging from 200-400 mg/day resulted in an improvement of FFA in $15 \%$ of cases, stabilization in $59 \%$, and worsening in $22 \%$ of cases $[2,27]$. Retinopathy, although rarely, might be an undesirable effect while using hydroxychloroquine chronically [27] (Tab. 7). For this reason, patients receiving this drug should be under ophthalmologic control. Other side-effects include gastrointestinal upset, headache, myopathy; however, hydroxychloroquine is safe in pregnancy $[5,63]$. It should be noted that the onset of action of the drug is slow, and a satisfactory response is usually obtained after 6-12 months of treatment $[5,64]$.

Doxycycline. Clinical response is usually lower and nonsatisfactory compared to other systemic treatment options $[5,27,59]$. Data in the literature show a positive response to doxycycline in $56 \%$ of cases, and more globally to antibiotics in $60 \%$ of cases (Tab. 6). Its use may be limited due to numerous side-effects, such as photosensitive reaction and gastrointestinal upset [5] (Tab. 7). 
Systemic retinoids. A retrospective cohort study of FFA patients was conducted, in which individuals treated with isotretinoin $20 \mathrm{mg} /$ day or acitretin $20 \mathrm{mg} /$ day for $12 \mathrm{months}$ showed stabilization, respectively, in 79\% (23/29) and 73\% (8/11) [65]. No further progression was seen after 12 months of treatment in $72 \%(21 / 29)$ of the patients on isotretinoin and $73 \%(8 / 11)$ of the patients on acitretin. No adverse sideeffects were reported in either group [5,65], although their teratogenic potential has to be taken into account (Tab. 7).

\section{Pioglitazone / peroxisome proliferator-activated receptor $\gamma$ (PPAR- $\gamma)$ agonists. Seldom used [2, 5, 27].}

Naltrexone. Sometimes proposed for treatment of FFA [27], but only one case reported [66].

Immunosuppressive therapy. Potent immunosuppressive agents such as oral prednisone, methotrexate and mycophenolate mofetil, present mixed results and are usually implemented for refractory cases of FFA [27].

Hair transplant. Often demonstrates early positive results after the procedure is performed. Nevertheless, only 33\% $(2 / 6)$ of reviewed patients showed lasting results 2 years after transplantation [27].

Additionally, the case was reported of 3 women with facial papules in the course of FFA [54], in which in addition to finasteride and various topical modalities already included in their treatment for FFA, a 3-months treatment of their facial papules with isotretinoin was decided $(20 \mathrm{mg} /$ day titrated to $40 \mathrm{mg} /$ day) [67]. The condition of all the women improved significantly after a month of treatment, and facial papules were minimum to non-existent after 3 months $[5,67]$. Although the areas over their hairlines still exhibited signs of FFA activity [54], the use of isotretinoin may be recommended for facial papules associated with FFA $[5,67]$.

To sum up, the highest level of evidence for the treatment of FFA is currently provided by $5 a$-RIs, intralesional steroids, and hydroxychloroquine [5, 27, 68] (Tab. 6). Unlike LPP, FFA shows poor response to topical and systemic steroids and other immunosuppressives [27, 54, 68] (Tab. 1, Tab. 6).

Eventually, one might consider the issue about the stabilization of FFA, whether it is spontaneous, as often seems to be the case [50], or it is the consequence of the effectiveness of an implemented treatment. Indeed, some authors consider that no treatment should be given to stabilized patients [50, 69], whereas others insist on the importance of implementing or continuing a treatment for the same patients, even if the results are not obvious or satisfactory, because of the benefits in terms of improving the appearance of the patient's scalp and quality of life, and because of the risk of serious and irreversible damages [48]. To reconcile these two opinions, it might be useful for clinicians to define the stability criteria for FFA, for example, no sign of continuing regression of frontal hairline during a determined period of time, or no inflammatory infiltration in biopsy [50]. In this case, patients with stabilized FFA should be excluded from future clinical studies in order to prove the effectiveness of implemented treatments with the adequate level of evidence [50].

For those more interested in details of the treatments reported in the literature, the treatment reviews for FFA made by Gamret, Potluri, Krishnamurthy et al. [5], Ho and
Shapiro [27], Imhof and Tolkachjov [68] and Rácz, and Gho, Moorman et al., are highly recommended [6]. An updated synthesis of their works is presented in Table 6 and should be considered next to the adverse effects reported in Table 7. Most sources are considered level $2 \mathrm{~b}$ evidence [27], others being rated $3 \mathrm{a}, 3 \mathrm{~b}$ or 4 according to the Oxford Centre for Evidence-based Medicine guidelines.

Additionally, in order to facilitate the choice by clinicians of a proper treatment approach, algorithms to the management of FFA derived from evidence in the literature have been proposed by Ho and Shapiro [27] and by Imhof and Tolkachjov [68] alongside their own clinical experiences. Assembling them turns out to be very useful (Fig. 4).

Moreover, it is important to emphasize that cicatricial alopecias are conditions with significant personal consequences and emotional impact. Considerable levels of psychological distress were observed as well as reduced quality of life, and additionally, durable hair loss can lower patient's self-confidence and self-esteem [70]. That is why, all patients should receive support and have access to psychological therapy, if needed.

There are a number of limitations to the current study. Firstly, its retrospective design and the heterogeneity of the assembled data due to their different origins, and to the lack of common, approved diagnostic criteria, scoring systems for categorizing disease severity, clinically-validated guidelines for treatment, protocols for evaluating therapeutic results, and following-up patients in the long-term. Exact data concerning incidence and prevalence of FFA are unavailable. Moreover, the pathogenesis is still unclear, especially with regard to environmental factors. Furthermore, there is a lack of evidence-based studies to guide treatment for patients with FFA [1]. Even the literature on treatment modalities is at an early stage, since it consists mostly of case reports and retrospective studies.

\section{SUMMARY}

FFA is considered a variant of LPP due to the similarity of the prominent histopathological findings [4]. Postmenopausal women are the most affected population. Chronic inflammation and perifollicular fibrosis are believed to be the primary causes of irreversible hair loss [27]. The dynamical increase in the incidence of FFA in recent years raises many questions about the potential factors involved in the pathogenesis of this condition. Autoimmune, genetic, hormonal and environmental hypotheses have been proposed for the pathogenesis, as well as association with predisposing factors such as patient's health-social profile, disease history and comorbidities. In women with FFA, association was found for pregnancy, lactation, HRT, raloxifene, hypothyroidism, LPP, rosacea, daily use of facial sunscreens, and occupational exposure to alkylphenolic chemicals. In men, association was found only with the daily use of facial sunscreens and anti-ageing cream [15].

However, the positive correlation reported by many authors between sunscreen use and FFA generates interest as well as controversy. Moreover, FFA is a newly-described and classified dermatological disorder, which is why it is crucial for physicians as well as dermatologists to know and be familiar with the characteristic clinical presentation of the disease, principles of diagnostic procedures and treatment 


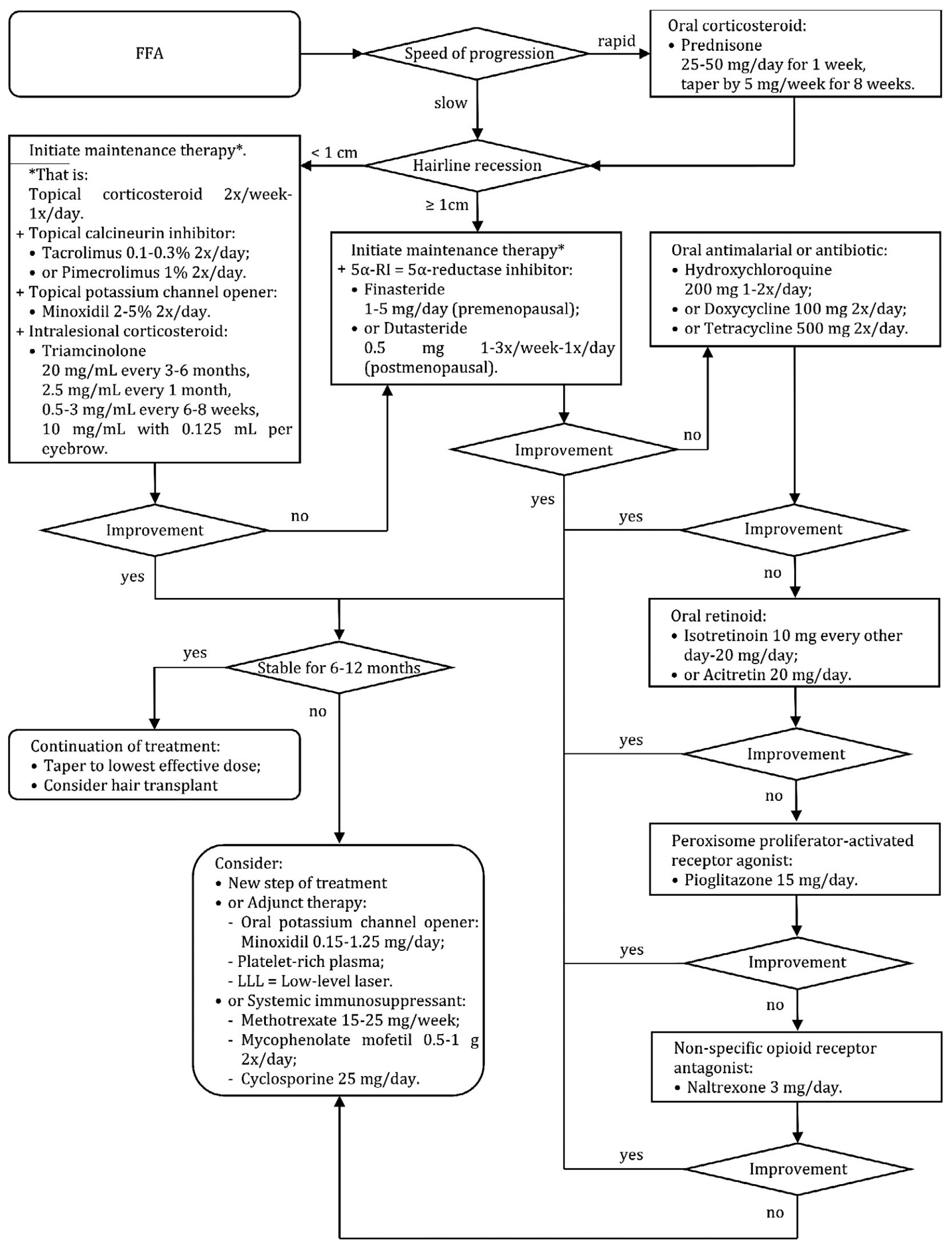

Figure 4. FFA treatment algorithm

Note: adapted from Ho and Shapiro [27] and Imhof and Tolkachjov [68].

Abbreviation: FFA - frontal fibrosing alopecia 
modalities. The clinical image of FFA can be divided into 3 specific patterns, each with a different prognosis. Diagnosis is made clinically with the aid of trichoscopy; however, skin biopsy is needed in case of doubt and remains the gold standard. Before recognizing FFA, detailed differential diagnosis should always be conducted. When the diagnosis is made, proper assessment of the severity of the disease is also necessary. Unfortunately, many patients are seen by specialist too late and with advanced recession of the frontotemporal hairline and features of FFA. This is the reason why a fast diagnosis and immediate implementation of treatment is required in order to stop damages, which may have a serious and irreversible impact on a patient's quality of life. The options for treating FFA vary, but $5 a$-RIs, intralesional steroids, and hydroxychloroquine possess the highest level of evidence for the treatment of FFA [5, 27, 68].

These issues could be the subjects of further research with a view to widening knowledge and comprehension of this challenging entity, which may be crucial to halt progression of the disease in individual patients, and prevent what appears to be an epidemic spread of this condition worldwide.

\section{REFERENCES}

1. Samrao A, Chew A-L, Price V. Frontal fibrosing alopecia: a clinical review of 36 patients. Br J Dermatol. 2010; 163(6): 1296-300. https:// doi.org/10.1111/j.1365-2133.2010.09965.x

2. Vañó-Galván S, Molina-Ruiz AM, Serrano-Falcón C, et al. Frontal fibrosing alopecia: a multicenter review of 355 patients. J Am Acad Dermatol. 2014; 70(4): 670-8. https://doi.org/10.1016/j.jaad.2013.12.003

3. MacDonald A, Clark C, Holmes S. Frontal fibrosing alopecia: a review of 60 cases. J Am Acad Dermatol. 2012; 67(5): 955-61. https://doi. org/10.1016/j.jaad.2011.12.038

4. Kossard S. Postmenopausal frontal fibrosing alopecia. Scarring alopecia in a pattern distribution. Arch Dermatol. 1994; 130(6): 770-4.

5. Gamret AC, Potluri VS, Krishnamurthy K, et al. Frontal fibrosing alopecia: efficacy of treatment modalities. Int J Womens Health. 2019; 11: 273-85. https://doi.org/10.2147/IJWH.S177308

6. Rácz E, Gho C, Moorman PW, et al. Treatment of frontal fibrosing alopecia and lichen planopilaris: a systematic review. J Eur Acad Dermatol Venereol. 2013; 27(12): 1461-70. https://doi.org/10.1111/ jdv.12139

7. Kossard S, Lee MS, Wilkinson B. Postmenopausal frontal fibrosing alopecia: a frontal variant of lichen planopilaris. J Am Acad Dermatol. 1997; 36(1): 59-66. https://doi.org/10.1016/s0190-9622(97)70326-8

8. Mirmirani P, Tosti A, Goldberg L, et al. Frontal Fibrosing Alopecia: An Emerging Epidemic. Skin Appendage Disord. 2019; 5(2): 90-3. https://doi.org/10.1159/000489793

9. Imhof RL, Chaudhry HM, Larkin SC, et al. Frontal Fibrosing Alopecia in Women: The Mayo Clinic Experience With 148 Patients, 1992 2016. Mayo Clin Proc. 2018; 93(11): 1581-8. https://doi.org/10.1016/j. mayocp.2018.05.036

10. Ormaechea-Pérez N, López-Pestaña A, Zubizarreta-Salvador J, et al. Frontal Fibrosing Alopecia in Men: Presentations in 12 Cases and a Review of the Literature. Actas Dermosifiliogr. 2016; 107(10): 836-44. https://doi.org/10.1016/j.ad.2016.07.004

11. Kanti V, Constantinou A, Reygagne P, et al. Frontal fibrosing alopecia: demographic and clinical characteristics of 490 cases. J Eur Acad Dermatol Venereol. 2019; 33(10): 1976-83. https://doi.org/10.1111/ jdv.15735

12. Ramos PM, Anzai A, Duque-Estrada B, et al. Risk factors for frontal fibrosing alopecia: A case-control study in a multiracial population. J Am Acad Dermatol. 2020; https://doi.org/10.1016/j.jaad.2020.08.076

13. Trüeb RM, Gavazzoni Dias MFR, Dutra Rezende H, et al. Comment on: Risk Factors for Frontal Fibrosing Alopecia: a Case-Control Study in a Multiracial Population. J Am Acad Dermatol. 2020; https://doi. org/10.1016/j.jaad.2020.10.096

14. Tan KT, Messenger AG. Frontal fibrosing alopecia: clinical presentations and prognosis. Br J Dermatol. 2009; 160(1): 75-9. https:// doi.org/10.1111/j.1365-2133.2008.08861.x
15. Moreno-Arrones OM, Saceda-Corralo D, Rodrigues-Barata AR, et al. Risk factors associated with frontal fibrosing alopecia: a multicentre case-control study. Clin Exp Dermatol. 2019; 44(4): 404-10. https:// doi.org/10.1111/ced.13785

16. Santoro N. Mechanisms of premature ovarian failure. Ann Endocrinol (Paris). 2003; 64(2): 87-92.

17. Moreno-Arrones OM, Saceda-Corralo D, Rodrigues-Barata AR, et al. Factors influencing frontal fibrosing alopecia severity: a multicentre cross-sectional study. J Eur Acad Dermatol Venereol. 2019; 33(9): e315-6. https://doi.org/10.1111/jdv.15590

18. Litaiem N, Idoudi S. Frontal Fibrosing Alopecia. In: StatPearls. Treasure Island (FL): StatPearls Publishing; 2020.

19. Lee JA, Levy DA, Patel KG, et al. Hair transplantation in frontal fibrosing alopecia and lichen planopilaris: A systematic review. Laryngoscope. 2020; https://doi.org/10.1002/lary.28551

20. Chiang YZ, Tosti A, Chaudhry IH, et al. Lichen planopilaris following hair transplantation and face-lift surgery. Br J Dermatol. 2012; 166(3): 666-70. https://doi.org/10.1111/j.1365-2133.2011.10692.x

21. Aldoori N, Dobson K, Holden CR, et al. Frontal fibrosing alopecia: possible association with leave-on facial skin care products and sunscreens; a questionnaire study. Br J Dermatol. 2016; 175(4): 762-7. https://doi.org/10.1111/bjd.14535

22. Holmes S. Frontal Fibrosing Alopecia. Skin Therapy Lett. 2016; 21(4): 5-7.

23. McSweeney SM, Christou EA, Dand N, et al. Frontal fibrosing alopecia: a descriptive cross-sectional study of 711 female cases from the U.K. Br J Dermatol. 2020; https://doi.org/10.1111/bjd.19399

24. Tziotzios C, Petridis C, Dand N, et al. Genome-wide association study in frontal fibrosing alopecia identifies four susceptibility loci including HLA-B ${ }^{\star}$ 07:02. Nat Commun. 2019; 10(1): 1150. https://doi.org/10.1038/ s41467-019-09117-w

25. Hu H, Zhang S, Lei X, et al. Estrogen leads to reversible hair cycle retardation through inducing premature catagen and maintaining telogen. PLoS ONE. 2012; 7(7): e40124. https://doi.org/10.1371/journal. pone. 0040124

26. Kodaman PH. Early menopause: primary ovarian insufficiency and surgical menopause. Semin Reprod Med. 2010; 28(5): 360-9. https:// doi.org/10.1055/s-0030-1262895

27. Ho A, Shapiro J. Medical therapy for frontal fibrosing alopecia: A review and clinical approach. J Am Acad Dermatol. 2019; 81(2): 568-80. https://doi.org/10.1016/j.jaad.2019.03.079

28. Tosti A, Piraccini BM, Iorizzo M, et al. Frontal fibrosing alopecia in postmenopausal women. J Am Acad Dermatol. 2005; 52(1): 55-60. https://doi.org/10.1016/j.jaad.2004.05.014

29. Robinson G, McMichael A, Wang SQ, et al. Sunscreen and frontal fibrosing alopecia: A review. J Am Acad Dermatol. 2020; 82(3): 723-8. https://doi.org/10.1016/j.jaad.2019.09.085

30. Debroy Kidambi A, Dobson K, Holmes S, et al. Frontal fibrosing alopecia in men: an association with facial moisturizers and sunscreens. Br J Dermatol. 2017; 177(1): 260-1. https://doi.org/10.1111/bjd.15311

31. Cranwell WC, Sinclair R. Sunscreen and facial skincare products in frontal fibrosing alopecia: a case-control study. Br J Dermatol. 2019; 180(4): 943-4. https://doi.org/10.1111/bjd.17354

32. Imhof RL, Larkin SC, Cantwell HM, et al. The association of frontal fibrosing alopecia with skin and hair care products: a survey-based case series of 56 patients seen at Mayo Clinic. J Am Acad Dermatol. 2020; https://doi.org/10.1016/j.jaad.2020.03.129

33. Brunet-Possenti F, Deschamps L, Colboc H, et al. Detection of titanium nanoparticles in the hair shafts of a patient with frontal fibrosing alopecia. J Eur Acad Dermatol Venereol. 2018; 32(12): e442-3. https:// doi.org/10.1111/jdv.14967

34. Felmingham C, Yip L, Tam M, et al. Allergy to sunscreen and leave-on facial products is not a likely causative mechanism in frontal fibrosing alopecia: perspective from contact allergy experts. Br J Dermatol. 2020; 182(2): 481-2. https://doi.org/10.1111/bjd.18380

35. Thompson CT, Chen ZQ, Kolivras A, et al. Identification of titanium dioxide on the hair shaft of patients with and without frontal fibrosing alopecia: a pilot study of 20 patients. Br J Dermatol. 2019; 181(1): 216-7. https://doi.org/10.1111/bjd.17639

36. Lademann J, Weigmann H, Rickmeyer C, et al. Penetration of titanium dioxide microparticles in a sunscreen formulation into the horny layer and the follicular orifice. Skin Pharmacol Appl Skin Physiol. 1999; 12(5): 247-56. https://doi.org/10.1159/000066249

37. Aerts O, Bracke A, Goossens A, et al. Titanium dioxide nanoparticles and frontal fibrosing alopecia: cause or consequence? J Eur Acad Dermatol Venereol. 2019; 33(1): e45-6. https://doi.org/10.1111/jdv.15161

38. Fonda-Pascual P, Saceda-Corralo D, Moreno-Arrones OM, et al. Frontal fibrosing alopecia and environment: may tobacco be protective? J Eur 
Acad Dermatol Venereol. 2017; 31(2): e98-9. https://doi.org/10.1111/ jdv.13817

39. Rudnicka L, Rakowska A. The increasing incidence of frontal fibrosing alopecia. In search of triggering factors. J Eur Acad Dermatol Venereol. 2017; 31(10): 1579-80. https://doi.org/10.1111/jdv.14582

40. Dhana A, Gumedze F, Khumalo NP. Regarding 'Frontal fibrosing alopecia: possible association with leave-on facial skincare products and sunscreens; a questionnaire study.' Br J Dermatol. 2017; 176(3): 836-7. https://doi.org/10.1111/bjd.15197

41. Ladizinski B, Bazakas A, Selim MA, et al. Frontal fibrosing alopecia: a retrospective review of 19 patients seen at Duke University. J Am Acad Dermatol. 2013; 68(5): 749-55. https://doi.org/10.1016/j. jaad.2012.09.043

42. Moreno-Arrones OM, Saceda-Corralo D, Fonda-Pascual P, et al. Frontal fibrosing alopecia: clinical and prognostic classification. J Eur Acad Dermatol Venereol. 2017; 31(10): 1739-45. https://doi.org/10.1111/ jdv.14287

43. Vañó-Galván S, Saceda-Corralo D, Moreno-Arrones ÓM, et al. Updated diagnostic criteria for frontal fibrosing alopecia. J Am Acad Dermatol. 2018; 78(1): e21-2. https://doi.org/10.1016/j. jaad.2017.08.062

44. Tolkachjov SN, Chaudhry HM, Imhof RL, et al. Reply to: "Updated diagnostic criteria for frontal fibrosing alopecia." J Am Acad Dermatol. 2018; 78(1): e23-4. https://doi.org/10.1016/j.jaad.2017.09.027

45. Tosti A, Miteva M, Torres F. Lonely hair: a clue to the diagnosis of frontal fibrosing alopecia. Arch Dermatol. 2011; 147(10): 1240. https:// doi.org/10.1001/archdermatol.2011.261

46. Rossi A, Grassi S, Fortuna MC, et al. Unusual patterns of presentation of frontal fibrosing alopecia: A clinical and trichoscopic analysis of 98 patients. Journal of the American Academy of Dermatology. 2017; 77(1): 172-4. https://doi.org/10.1016/j.jaad.2017.02.012

47. Donati A, Molina L, Doche I, et al. Facial papules in frontal fibrosing alopecia: evidence of vellus follicle involvement. Arch Dermatol. 2011; 147(12): 1424-7. https://doi.org/10.1001/archdermatol.2011.321

48. Moreno-Ramirez D, Camacho Martinez F. Frontal fibrosing alopecia: a survey in 16 patients. J Eur Acad Dermatol Venerol. 2005; 19(6): 700-5. https://doi.org/10.1111/j.1468-3083.2005.01291.x

49. Holmes S, Ryan T, Young D, et al. Frontal Fibrosing Alopecia Severity Index (FFASI): a validated scoring system for assessing frontal fibrosing alopecia. Br J Dermatol. 2016; 175(1): 203-7. https://doi.org/10.1111/ bjd. 14445

50. Rallis E, Gregoriou S, Christofidou E, et al. Frontal fibrosing alopecia: to treat or not to treat? J Cutan Med Surg. 2010; 14(4): 161-6. https:// doi.org/10.2310/7750.2010.09041

51. Alegre-Sánchez A, Saceda-Corralo D, Bernárdez C, et al. Frontal fibrosing alopecia in male patients: a report of 12 cases. Journal of the European Academy of Dermatology and Venereology. 2017; 31(2): e112-4. https://doi.org/10.1111/jdv.13855

52. Melo DF, de Mattos Barreto T, de Souza Albernaz E, et al. Ten clinical clues for the diagnosis of frontal fibrosing alopecia. Indian J Dermatol Venereol Leprol. 2019; 85(5): 559-64. https://doi.org/10.4103/ijdvl. IJDVL_713_17

53. Waśkiel A, Rakowska A, Sikora M, et al. Trichoscopy in lichen planopilaris: an update. Przegl Dermatol. 2018; 105(1): 63-75. https:// doi.org/10.5114/dr.2018.74167

54. Tavakolpour S, Mahmoudi H, Abedini R, et al. Frontal fibrosing alopecia: An update on the hypothesis of pathogenesis and treatment. Int J Womens Dermatol. 2019; 5(2): 116-23. https://doi.org/10.1016/j. ijwd.2018.11.003

55. Moreno-Arrones OM, Alfageme F, Alegre A, et al. Ultrasonographic Characteristics of Frontal Fibrosing Alopecia. Int J Trichology. 2019; 11(4): 183-4. https://doi.org/10.4103/ijt.ijt $58 \quad 19$

56. Donati A, Gupta AK, Jacob C, et al. The Use of Direct Immunofluorescence in Frontal Fibrosing Alopecia. Skin Appendage Disord. 2017; 3(3): 125-8. https://doi.org/10.1159/000469665

57. Tolkachjov SN, Chaudhry HM, Camilleri MJ, et al. Frontal fibrosing alopecia among men: A clinicopathologic study of 7 cases. J Am Acad Dermatol. 2017; 77(4): 683-690.e2. https://doi.org/10.1016/j. jaad.2017.05.045

58. Saceda-Corralo D, Moreno-Arrones ÓM, Fonda-Pascual P, et al. Development and validation of the Frontal Fibrosing Alopecia Severity Score. J Am Acad Dermatol. 2018; 78(3): 522-9. https://doi. org/10.1016/j.jaad.2017.09.034

59. Strazzulla LC, Avila L, Li X, et al. Prognosis, treatment, and disease outcomes in frontal fibrosing alopecia: A retrospective review of 92 cases. J Am Acad Dermatol. 2018; 78(1): 203-5. https://doi.org/10.1016/j. jaad.2017.07.035
60. Srivastava S, Patil AN, Prakash C, et al. Comparison of Intralesional Triamcinolone Acetonide, 5-Fluorouracil, and Their Combination for the Treatment of Keloids. Adv Wound Care (New Rochelle). 2017; 6(11): 393-400. https://doi.org/10.1089/wound.2017.0741

61. Babahosseini H, Tavakolpour S, Mahmoudi H, et al. Lichen planopilaris: retrospective study on the characteristics and treatment of 291 patients. J Dermatol Treatment. 2019; 30(6): 598-604. https://doi.org/10.1080/ 09546634.2018.1542480

62. Rogers NE, Avram MR. Medical treatments for male and female pattern hair loss. J Am Acad Dermatol. 2008; 59(4): 547-66; quiz 567-8. https:// doi.org/10.1016/j.jaad.2008.07.001

63. Fertig R, Aleid NM, Tosti A. Therapeutic options in frontal fibrosing alopecia. Expert Opinion on Orphan Drugs. 2016; 4(5): 461-8. https:// doi.org/10.1517/21678707.2016.1173539

64. Van Beek MJ, Piette WW. Antimalarials. Dermatol Clin. 2001; 19(1): 147-60, ix. https://doi.org/10.1016/s0733-8635(05)70236-9

65. Rakowska A, Gradzińska A, Olszewska M, et al. Efficacy of Isotretinoin and Acitretin in Treatment of Frontal Fibrosing Alopecia: Retrospective Analysis of 54 Cases. J Drugs Dermatol. 2017; 16(10): 988-92.

66. Strazzulla LC, Avila L, Lo Sicco K, et al. Novel Treatment Using LowDose Naltrexone for Lichen Planopilaris. J Drugs Dermatol. 2017; 16(11): 1140-2.

67. Pirmez R, Duque-Estrada B, Barreto T, et al. Successful Treatment of Facial Papules in Frontal Fibrosing Alopecia with Oral Isotretinoin. Skin Appendage Disord. 2017; 3(2): 111-3. https://doi. org/10.1159/000464334

68. Imhof R, Tolkachjov SN. Optimal Management of Frontal Fibrosing Alopecia: A Practical Guide. CCID. 2020; 13: 897-910. https://doi. org/10.2147/CCID.S235980

69. Rigopoulos D, Rallis E, Gregoriou S, et al. Reassessing frontal fibrosing alopecia. Exp Rev Dermatol. 2008; 3(5): 605-12. https://doi. org/10.1586/17469872.3.5.605

70. Chiang YZ, Bundy C, Griffiths CEM, et al. The role of beliefs: lessons from a pilot study on illness perception, psychological distress and quality of life in patients with primary cicatricial alopecia. Br J Dermatol. 2015; 172(1): 130-7. https://doi.org/10.1111/bjd.13259

71. Martínez-Pérez M, Churruca-Grijelmo M. Frontal Fibrosing Alopecia: An Update on Epidemiology and Treatment. Actas Dermo-Sifiliográficas. 2015; 106(9): 757-8. https://doi.org/10.1016/j.ad.2014.12.002

72. Ranasinghe GC, Piliang MP, Bergfeld WF. Prevalence of hormonal and endocrine dysfunction in patients with lichen planopilaris (LPP): A retrospective data analysis of 168 patients. J Am Acad Dermatol. 2017; 76(2): 314-20. https://doi.org/10.1016/j.jaad.2016.05.038

73. Poblet E, Jiménez F, Pascual A, et al. Frontal fibrosing alopecia versus lichen planopilaris: a clinicopathological study. Int J Dermatol. 2006; 45(4): 375-80. https://doi.org/10.1111/j.1365-4632.2006.02507.x

74. Gálvez-Canseco A, Sperling L. Lichen planopilaris and frontal fibrosing alopecia cannot be differentiated by histopathology. J Cutaneous Pathol. 2018; 45(5): 313-7. https://doi.org/10.1111/cup.13112

75. Pedrosa AF, Duarte AF, Haneke E, et al. Yellow facial papules associated with frontal fibrosing alopecia: A distinct histologic pattern and response to isotretinoin. J Am Acad Dermatol. 2017; 77(4): 764-6. https://doi.org/10.1016/j.jaad.2017.04.1118

76. Chiang C, Sah D, Cho BK, et al. Hydroxychloroquine and lichen planopilaris: Efficacy and introduction of Lichen Planopilaris Activity Index scoring system. J Am Acad Dermatol 2010; 62(3): 387-92. https:// doi.org/10.1016/j.jaad.2009.08.054

77. Donati A, Lindgren B, Abreu G, et al. Prevalence of frontal fibrosing alopecia among Brazilian dermatologists: A cross-sectional survey. JAAD International. 2020; 1: 148-50. https://doi.org/10.1016/j. jdin.2020.07.008

78. Ghafoor R, Khoso BK, Anwar M, et al. Graham-Little-PiccardiLassueur syndrome: A rare case report and review of literature. 2015; 25: 327-30.

79. Zhang M, Zhang L, Rosman IS, et al. Frontal fibrosing alopecia demographics: a survey of 29 patients. Cutis. 2019; 103(2): E16-22.

80. Maldonado Cid P, Leis Dosil VM, Garrido Gutiérrez C, et al. Frontal Fibrosing Alopecia: A Retrospective Study of 75 Patients. Actas Dermosifiliogr. 2020; 111(6): 487-95. https://doi.org/10.1016/j. adengl.2020.03.014

81. Naz E, Vidaurrázaga C, Hernández-Cano N, et al. Postmenopausal frontal fibrosing alopecia. Clin Experimental Dermatol. 2003; 28(1): 25-7.

82. Banka N, Mubki T, Bunagan MJK, et al. Frontal fibrosing alopecia: a retrospective clinical review of 62 patients with treatment outcome and long-term follow-up. Int J Dermatol. 2014; 53(11): 1324-30. https:// doi.org/10.1111/ijd.12479 
83. Pindado-Ortega C, Saceda-Corralo D, Moreno-Arrones OM, et al. Effectiveness of Dutasteride in a Large Series of Patients with Frontal Fibrosing Alopecia in Real Clinical Practice. J Am Acad Dermatol. 2020; https://doi.org/10.1016/j.jaad.2020.09.093

84. Pham CT, Hosking A-M, Cox S, et al. Therapeutic response of facial papules and inflammation in frontal fibrosing alopecia to low-dose oral isotretinoin. JAAD Case Reports. 2020; 6(5): 453-6. https://doi. org/10.1016/j.jdcr.2020.01.030

85. Cranwell WC, Sinclair R. Frontal fibrosing alopecia: Regrowth following cessation of sunscreen on the forehead. Aust J Dermatol. 2019; 60(1): 60-1. https://doi.org/10.1111/ajd.12833

86. Faulkner CF, Wilson NJ, Jones SK. Frontal fibrosing alopecia associated with cutaneous lichen planus in a premenopausal woman. Austr J Dermatol. 2002; 43(1): 65-7. https://doi.org/10.1046/j.14400960.2002.00558.x

87. Özcan D, Vural AT, Özen Ö. Platelet-rich plasma for treatment resistant frontal fibrosing alopecia: A case report. Dermatologic Therapy. 2019; 32(5): e13072. https://doi.org/10.1111/dth.13072

88. Donovan JC. Finasteride-mediated hair regrowth and reversal of atrophy in a patient with frontal fibrosing alopecia. JAAD Case Reports. 2015; 1(6): 353-5. https://doi.org/10.1016/j.jdcr.2015.08.003

89. Gurfinkiel A, Igarza HG, Casas J, et al. Hair transplantation in a patient with frontal fibrosing alopecia associated with lichen scleroatrophicus vulvae. Dermatol Argent. 2011; 17(2): 110-5.

90. Heppt MV, Letulé V, Laniauskaite I, et al. Frontal Fibrosing Alopecia: A Retrospective Analysis of 72 Patients from a German Academic Center. Facial Plast Surg. 2018; 34(1): 88-94. https://doi. org/10.1055/s-0037-1615281

91. Clark-Loeser L, Latkowski J-A. Frontal fibrosing alopecia. Dermatology Online Journal. 2005; 11(4)

92. Dawn G, Holmes SC, Moffat D, et al. Post-menopausal frontal fibrosing alopecia. Clin Experimental Dermatol. 2003; 28(1): 43-5.

93. Liu Y-CS, Jee S-H, Chan J-YL. Hair transplantation for the treatment of lichen planopilaris and frontal fibrosing alopecia: A report of two cases. Austr J Dermatol. 2018; 59(2): e118-22. https://doi.org/10.1111/ ajd.12682

94. Mahmoudi H, Rostami A, Tavakolpour S, et al. Oral isotretinoin combined with topical clobetasol $0.05 \%$ and tacrolimus $0.1 \%$ for the treatment of frontal fibrosing alopecia: a randomized controlled trial. J Dermatol Treat. 2020; [published online ahead of print]: 1-7. https:// doi.org/10.1080/09546634.2020.1750553

95. Katoulis A, Georgala S, Bozi E, et al. Frontal fibrosing alopecia: treatment with oral dutasteride and topical pimecrolimus. J Eur Acad Dermatol Venereol. 2009; 23(5): 580-2. https://doi.org/10.1111/j.14683083.2008.02963.x

96. Mesinkovska NA, Tellez A, Dawes D, et al. The use of oral pioglitazone in the treatment of lichen planopilaris. J Am Acad Dermatol. 2015; 72(2): 355-6. https://doi.org/10.1016/j.jaad.2014.10.036

97. Jiménez F, Poblet E. Is hair transplantation indicated in frontal fibrosing alopecia? The results of test grafting in three patients. Dermatol Surg. 2013; 39(7): 1115-8. https://doi.org/10.1111/dsu.12232
98. Nusbaum BP, Nusbaum AG. Frontal fibrosing alopecia in a man: results of follicular unit test grafting. Dermatol Surg. 2010; 36(6): 959-62. https://doi.org/10.1111/j.1524-4725.2010.01580.x

99. Batra P, Sukhdeo K, Shapiro J. Hair Loss in Lichen Planopilaris and Frontal Fibrosing Alopecia: Not Always Irreversible. Skin Appendage Disord. 2020; 6(2): 125-9. https://doi.org/10.1159/000505439

100.Donovan JC, Samrao A, Ruben BS, et al. Eyebrow regrowth in patients with frontal fibrosing alopecia treated with intralesional triamcinolone acetonide: Correspondence. Brit J Dermatol. 2010; 163(5): 1142-4. https://doi.org/10.1111/j.1365-2133.2010.09994.x

101. Cranwell WC, Sinclair R. Familial frontal fibrosing alopecia treated with dutasteride, minoxidil and artificial hair transplantation. Austral J Dermatol. 2017; 58(3): e94-6. https://doi.org/10.1111/ajd.12499

102.Pérez-Rodríguez IM, García-Melendez ME, Eichelmann K, et al. Hyperpigmentation following Treatment of Frontal Fibrosing Alopecia. Case Rep Dermatol. 2013; 5(3): 357-62. https://doi. org/10.1159/000357022

103. Vañó-Galván S, Villodres E, Pigem R, et al. Hair transplant in frontal fibrosing alopecia: A multicenter review of 51 patients. J Am Acad Dermatol. 2019; 81(3): 865-6. https://doi.org/10.1016/j.jaad.2019.05.031

104.Audickaite A, Alam M, Jimenez F. Eyebrow Hair Transplantation in Frontal Fibrosing Alopecia: Pitfalls of Short- and Long-Term Results. Dermatol Surg. 2020; 46(7): 922-5. https://doi.org/10.1097/ DSS.0000000000002207

105.Ledford D, Broder MS, Antonova E, et al. Corticosteroid-related toxicity in patients with chronic idiopathic urticaria-chronic spontaneous urticaria. Allergy Asthma Proc. 2016; 37(6): 458-65. https://doi.org/10.2500/aap.2016.37.3999

106.Fertig R, Tosti A. Frontal fibrosing alopecia treatment options. Intractable Rare Dis Res. 2016; 5(4): 314-5. https://doi.org/10.5582/ irdr.2016.01065

107. Murad A, Bergfeld W. 5-alpha-reductase inhibitor treatment for frontal fibrosing alopecia: an evidence-based treatment update. J Eur Acad Dermatol Venereol. 2018; 32(8): 1385-90. https://doi.org/10.1111/ jdv. 14930

108. Hirshburg JM, Kelsey PA, Therrien CA, et al. Adverse Effects and Safety of 5-alpha Reductase Inhibitors (Finasteride, Dutasteride): A Systematic Review. J Clin Aesthet Dermatol. 2016; 9(7): 56-62.

109. McLane J. Analysis of common side effects of isotretinoin. J Am Acad Dermatol. 2001; 45(5): S188-194. https://doi.org/10.1067/ mjd.2001.113719

110. Wong E, Kurian A. Off-Label Uses of Topical Calcineurin Inhibitors. Skin Therapy Lett. 2016; 21(1): 8-10.

111. Li Z, You Y, Griffin N, et al. Low-dose naltrexone (LDN): A promising treatment in immune-related diseases and cancer therapy. International Immunopharmacology. 2018; 61: 178-84. https://doi.org/10.1016/j. intimp.2018.05.020

112. Wang W, Zhou H, Liu L. Side effects of methotrexate therapy for rheumatoid arthritis: A systematic review. Eur J Med Chem. 2018; 158: 502-16. https://doi.org/10.1016/j.ejmech.2018.09.027

113. Chen T-J, Chung W-H, Chen C-B, et al. Methotrexate-induced epidermal necrosis: A case series of 24 patients. J Am Acad Dermatol. 2017; 77(2): 247-255.e2. https://doi.org/10.1016/j.jaad.2017.02.021 